\title{
A RESEARCH ON EVALUATING THE EFFECT OF APPLYING GASOLINE ENGINE WITH EARLY OPENING AND LATELY CLOSING \\ VAVLE ON HYBRID VEHICLE
}

\section{VANTUAN NGUYEN}

University of Transport Technology, Hanoi City, Vietnam

\begin{abstract}
When switching to a hybrid car, the regular working area of the heat engine will be altered, which is higherfuel consumption section of the engine. One of the solutions to reduce fuel consumption is to adjust the opening angle early, late closing of the valve to fit the regular work area of the engine. This article presents the results of calculating the early opening angle, late closing of the valve in accordance with the regular work area. To evaluate the efficiency of the engine using the new camshaft, the study carried out the installation of camshafts on the engine and test run. At this stage of operation, with the early opening angle, the delayed opening of the engine valve has reduced fuel consumption compared to the original engine at all speed modes. Especially in the speed mode $n=2300$ [rpm], M= 26 [N. $m$ ], the maximum fuel consumption is reduced to 7.8\%. Fuel consumption throughout the region at $M=26$ [N. $m$ ] average decreased by $6.3 \%$. The amount of $\mathrm{CO}$ and $\mathrm{HC}$ significantly reduced compared to the original engine, while NOx increased slightly.
\end{abstract}

KEYWORDS: Internal Combustion Engine, Hybrid Car, Regular Operation Region \& Exhaust

Received: Nov 10, 2018; Accepted: Nov 30, 2018; Published: Dec 20, 2018; Paper Id.: IJMPERDFEB20193

\section{INTRODUCTION}

Nowadays, when the world is faced with big problems like environmental pollution, exhausted fossil fuel sources, etc., the research on improving the engine structure, use new energy sources and fuel for cars is essential. Some studies have shown that when changing the valve timing, the energy and environmental parameters are improved as studied [1,2], showing the effect of time of intake valve closing (IVC) on a performance like Torque and power, fuel consumption. The engine used in the study was a four-stroke gasoline engine that has four cylinders with a capacity of 1.6 liter and has a lateral angle of intake varying from $210 \div 550$. The results show that the timing of closing the intake valve plays an important role in increasing the power and reducing fuel consumption of the engine, while the $100 \%$ loading at low torque increases by about $11 \%$, at high torque increased by about $7 \%$. On the other hand, research shows that although fuel economy improves over the entire range, the most effective time of the IVC in engine power is in the heavy load mode from $60 \%$, especially over $80 \%$. Study [3] on change of valve timing and the compression ratio. The research team used a 1.8L AVL test engine, a compression ratio varying from $8 \div 10$, and the maximum slow IVC angle of $32 \div 45$ degrees crankshaft rotation. The results show that fuel consumption can be reduced by more than $10 \%$ when the car is operating in the city cycle. The study also confirms the change of valve timing (VVT) plays an important role in increasing efficiency and reducing fuel consumption when operating at high loading mode, high speed. 
When using variable compression ratio (VCR), the engine performs well in light load and partial load. For the most fuel-efficient motor operation, harmonious combination between change of valve timing and compression ratios is required to suit the operating mode of the engine. A study by Hara et al. [4] suggested that to reduce the "pump" of the petrol engine and to improve the fuel economy at the partial loading mode, it is necessary to use solution to change intake valve-closing timing to be late. To investigate the effect of the late valve-closing angle to the losses in "pump", the team conducted a test on a four-cylinder gasoline engine with 1.7 liters capacity. The results show that with the late closing angle of the intake valve is 100 degrees of crankshaft rotation, the pump is reduced by $24 \%$ compared to the original pump.

Nobuki Kawamoto et al. [5] presented the results of applying the Atkinson cycle combined with exhaust gas recirculation on a 1.8-liter 2ZR-FXE engine. When changing late closing angle of the intake valve from 61 degrees of crankshaft rotation to 102 degrees of crankshaft rotation, the fuel consumption is reduced by $8.5 \%$ and when changing the valve timing combined with exhaust gas recirculation, the fuel consumption is reduced by $10.2 \%$ compared to engine with the low compression ratio and changing the base valve timing.

Hybrid cars are increasingly being researched and developed because of lower fuel consumption and emissions than cars equipped with internal combustion engines. Due to the support of electric motors, the internal combustion engine used in hybrid vehicles has its own characteristics compared to traditional car engines. Working mode of the gasoline engine in the hybrid car is the part load, in this mode the engine has high fuel consumption [6, 7, 8, 9 \& 10]. Some studies have shown that in order to improve this mode it is possible to use an increase late valve closing angle. Therefore, this article goes into determining the regular work area, from which to calculate, design, manufacture and give the engine with the new valve timing a test run.

\section{DESIGN AND MANUFACTURE NEW CAMSHAFTS}

\section{Regular Operation Region of the Engine}

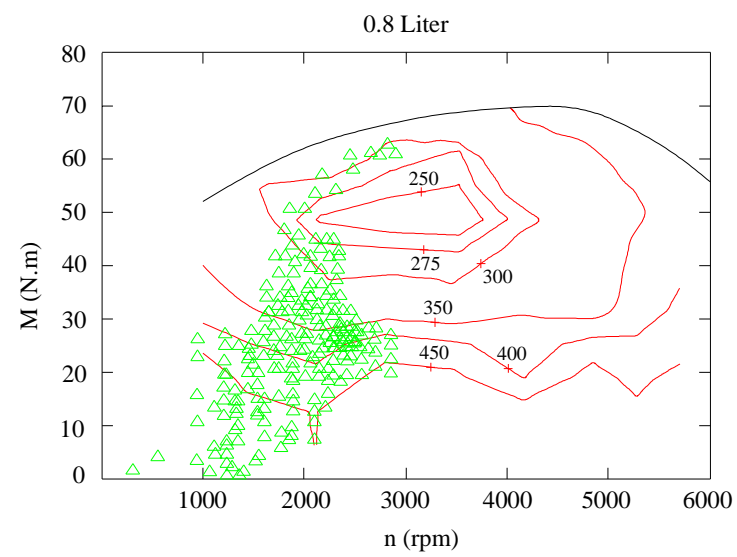

Figure 1: The Results of the Simulation Work Area Often NEDC Cycle

After building and data entry for the driving hybrid model using the 0.8 Liter gasoline engine mounted on a hybrid vehicle by Advisor software, run the model to get the results. The simulation result is shown in Figure 1.

Figure 1 shows that the gasoline engine in a hybrid car has a regular work area as part load. This area has a high density of gasoline engine operation and has a narrow speed range from $\mathrm{n}=1200$ [rpm] to $\mathrm{n}=3000$ [rpm], moment from $\mathrm{M}=18[\mathrm{Nm}]$ to $\mathrm{M}=36[\mathrm{Nm}]$ with fuel consumption change from ge $=275[\mathrm{~g} / \mathrm{kW} . \mathrm{h}]$ to ge $=450[\mathrm{~g} / \mathrm{kW}$. h]. This area is used to calculate the valve timing of the engine used in hybrid vehicles. 


\section{Calculation of Valve Timing and Camshaft Design}

With the aim of improving the working cycle of the engine to reduce fuel consumption, it is necessary to determine the proper mixing of the new working area to design a new camshaft suitable for the area. This study uses a 0.8 liter engine with the specifications shown in Table 1.

Table 1: Engine Specification Sheet

\begin{tabular}{|c|l|c|c|c|l|c|l|}
\hline NO & Specification & Value & Unit & NO & Specification & Value & Unit \\
\hline 1 & Capacity & 0,796 & liter & 6 & $\begin{array}{l}\text { Number of revolutions } \\
\mathrm{n}_{\mathrm{e}}\end{array}$ & 4600 & $\mathrm{rpm}$ \\
\hline 3 & $\begin{array}{l}\text { Compression } \\
\text { ratio }\end{array}$ & 9,3 & 7 & early ignition angle & 10 & $\begin{array}{l}\text { degrees of } \\
\text { crankshaft } \\
\text { rotation }\end{array}$ \\
\hline 4 & $\begin{array}{l}\text { Nower } \mathrm{N}_{\mathrm{emax}} \\
\text { revolutions } \mathrm{n}_{\mathrm{eN}}\end{array}$ & 67,5 & $\mathrm{~kW}$ & 8 & $\begin{array}{l}\text { Early opening and } \\
\text { lately closing angle of } \\
\text { intake valve }\end{array}$ & $10 ; 70 \begin{array}{l}\text { degrees of } \\
\text { crankshaft } \\
\text { rotation }\end{array}$ \\
\hline 5 & ${\text { Moment } \mathrm{M}_{\mathrm{emax}}}$ & 68,6 & $\mathrm{Nm}$ & & $\begin{array}{l}\text { Early opening and } \\
\text { lately closing angle of } \\
\text { exhaust valve }\end{array}$ & $70 ; 10$ & $\begin{array}{l}\text { degrees of } \\
\text { crankshaft } \\
\text { rotation }\end{array}$ \\
\hline
\end{tabular}

In fact, the energy balance method is often used to calculate the simulation of the engine's working cycle. In the simulation, calculating the working cycle of the engine for the purpose of defining economic, energy and environmental norms, one usually uses non-dimensional or one-dimensional models with single-location, two -location or multiple location. In the study using the 0.8 liter gasoline engine has a Fractal multi-region combustion model, this is a combustion model dedicated to use calculations for gasoline engines; The heat transfer model using the convective heat transfer coefficient $\alpha$ is determined by the Woschni 1978 model. From the structural analysis, the model was constructed by the AVL Boost software.

For the above analysis, the calculation mode is chosen to be speed $\mathrm{n}=2300[\mathrm{rpm}]$, moment $\mathrm{M}=26[\mathrm{~N}$. $\mathrm{m}]$. Based on the AVL Boost software, changes were made to the operating parameters of the 0.8 liter engine when the early opening angle of exhaust valve was shortened from 70 to 25 degrees of crankshaft rotation ; lately closing angle of intake valve increased from 60 to 100 degrees of crankshaft rotation. After calculating the above results, with the early opening angle of exhaust valve of 35 degrees of crankshaft rotation and late closing angle of intake valve of 90 degrees of crankshaft rotation angle, the engine has the maximum torque Me of $28.07[\mathrm{Nm}]$ and the smallest fuel consumption ge (362 [g/kW. h]). This is a reasonable valve timing of motors in the selected calculation mode.

\section{Manufacturing New Camshafts}

With the new valve timing defined above, the cam profile should be optimized. This is done using the AVL Excite software. Within the limits of the article cannot fully describe the calculated content, only the results of defining the new intake camshaft and new exhaust camshaft profile as shown in Figure 2. 


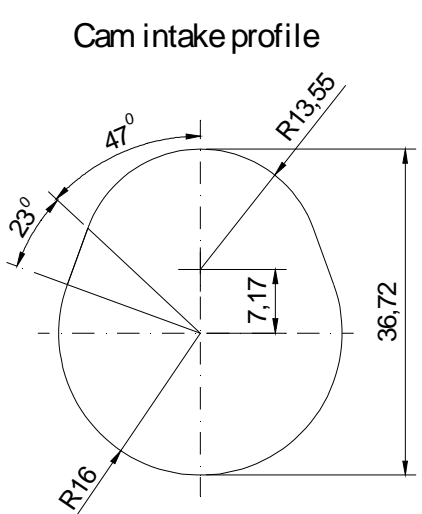

Cam exhaust profile

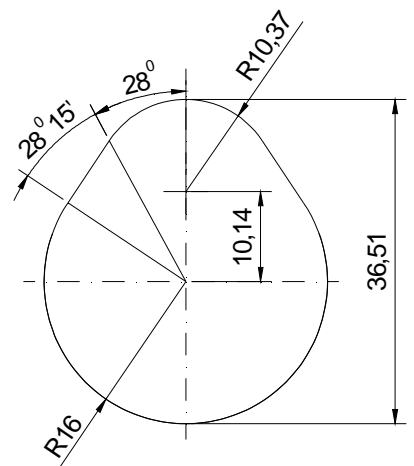

Figure 2: New Intake Camshaft and Exhaust Camshaft Profiles

After the design calculations, camshafts manufactured on CNC 5-axis results shown in Figure 3. Then check camshafts are precision by specialized equipment. Test results show that post-production camshafts meet the design requirements.

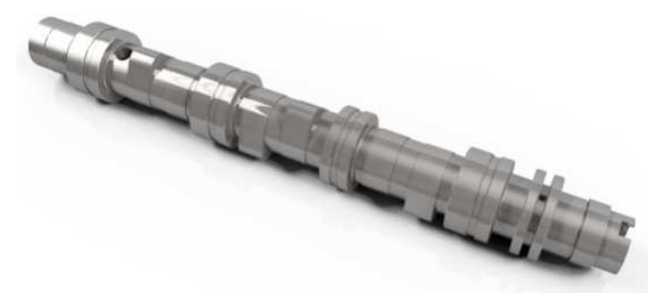

Figure 3: New Camshaft after Machining

\section{TESTING EQUIPMENT}

\section{Diagram of Experimental}

To test the original engine and the engine after changing the valve timing, the author used the experimental diagram shown in Figure 4.

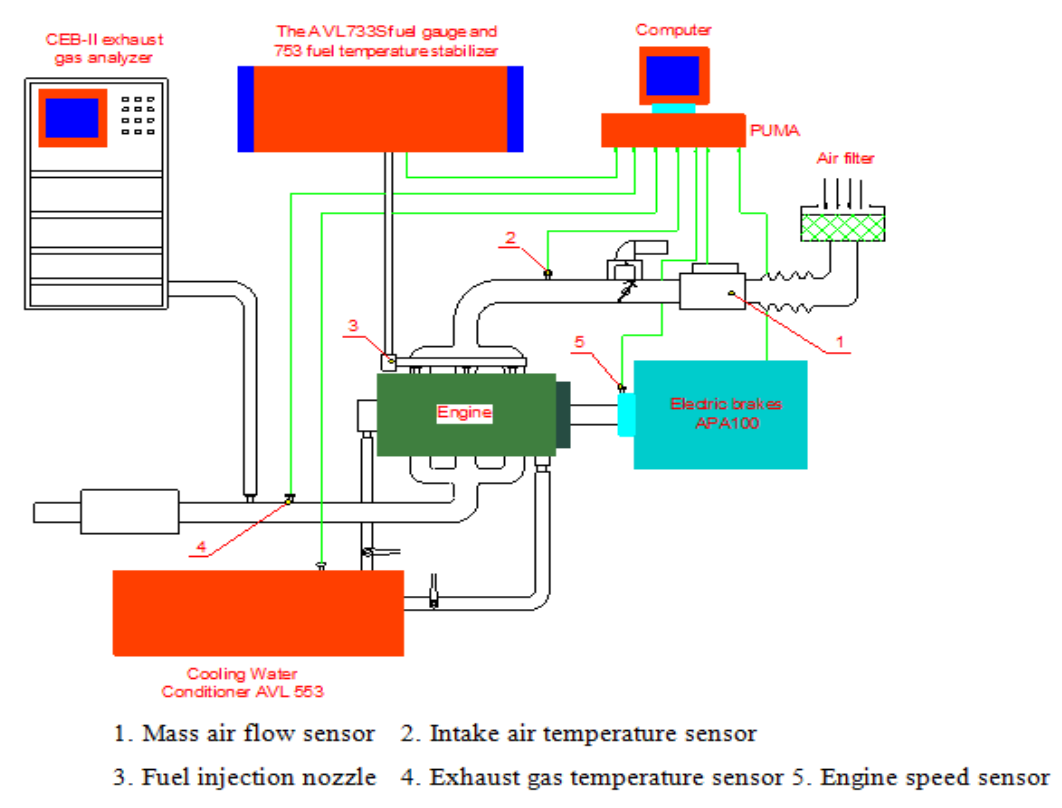

Figure 4: Diagram of Arrangement the Experimental Equipment 
This diagram is installed on the test strip of the internal combustion engine laboratory that is provided by AVL of Austria. Test strips are controlled via PUMA software and connected to a PC. PUMA software recognizes signals from sensors mounted on the test strips and mounts on the motor through the converter box. Sensor signals are converted to the computer screen to help the operator control the work of the engine. The process of changing the speed and torque of the engine is carried out through the control panel. The APA E100 electric scooter (using three-phase asynchronous squirrel cage motor) is manufactured by AVL with a maximum output of $200 \mathrm{~kW}$. With a speed range of $0 \div 8000 \mathrm{rpm}$, the working temperature is from $+5 \div+45^{0} \mathrm{C}$.

Basic equipment used for experiments:

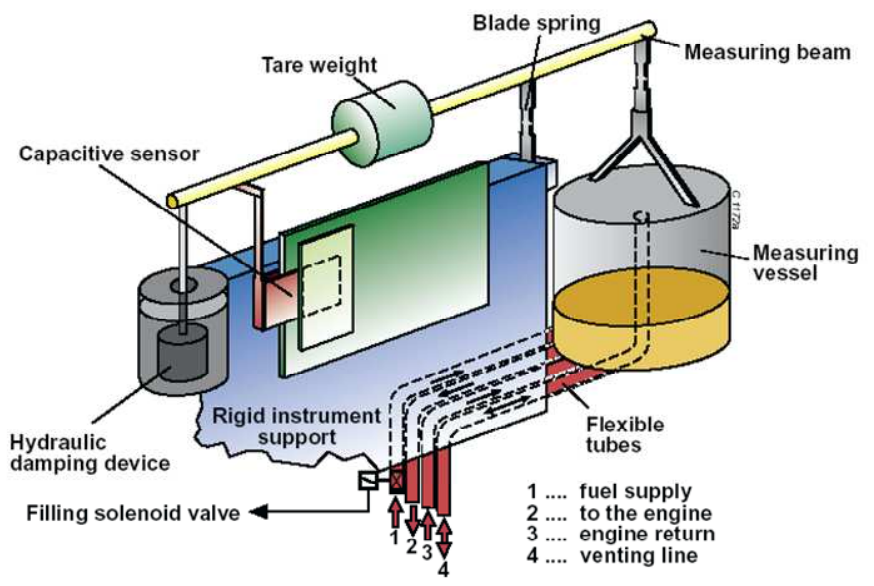

Figure 5: Operational Diagram of the $733 S$

The AVL Fuel Balance 733S uses the principle of weight measurement, thus can correct the error due to the influence of density and fuel temperature. Device error is $0.1 \%$. It is shown in Figure 5

\section{CEB II Exhaust Gas Analyzer}

Combustion Emission Bench (CEB-II) is a system that consists of a complete set of modules that perform the analysis of exhaust gas components (analyzers) and equipment that maintains the main working conditions of the system such as: Heating block (HSU), diagnostic block, control block.... In addition, the cabinet is equipped with an industrial computer with GEM110 control software. Connecting the control computer to the analyser is done via digital signals, depending on the analyzer that can be connected to the computer via CAN LON or RS232 serial cable. Analysers installed in the cabinet are used to measure components in the exhaust gases such as carbon monoxide $(\mathrm{CO})$, carbon dioxide $\left(\mathrm{CO}_{2}\right)$, oxygen $\left(\mathrm{O}_{2}\right)$, nitrogen oxides ( $\mathrm{NO}$ and $\mathrm{NOx}$ ), carbon hydrides $(\mathrm{HC})$, while also measure the excess air ratio of $0.1 \%$ accuracy. It is shown in Figure 6, Figure 7, Figure 8. 


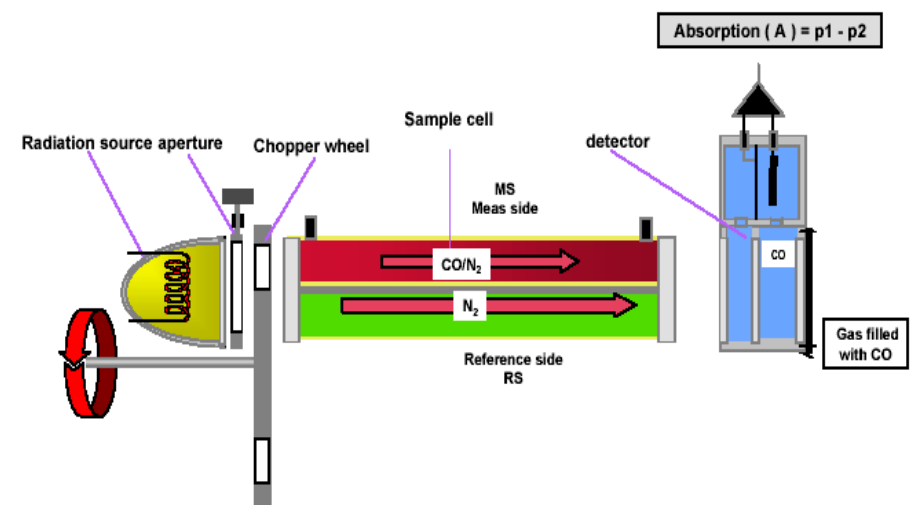

Figure 6: Principle Diagram of the CO Analyzer

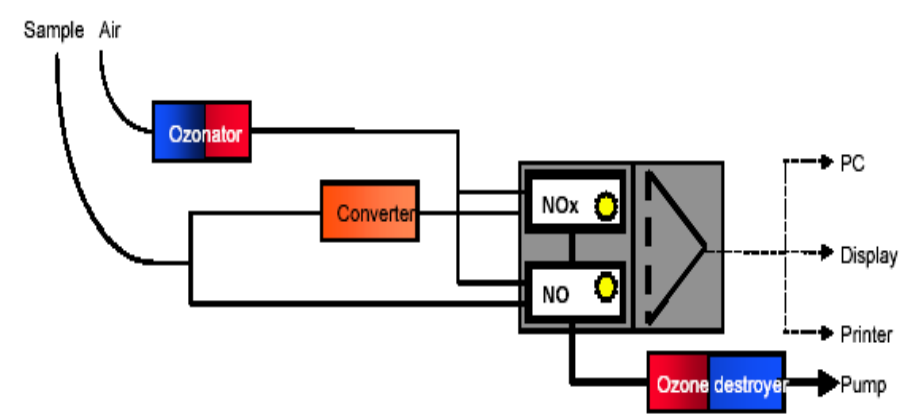

Figure 7: Principle of NO and NOx Analysis
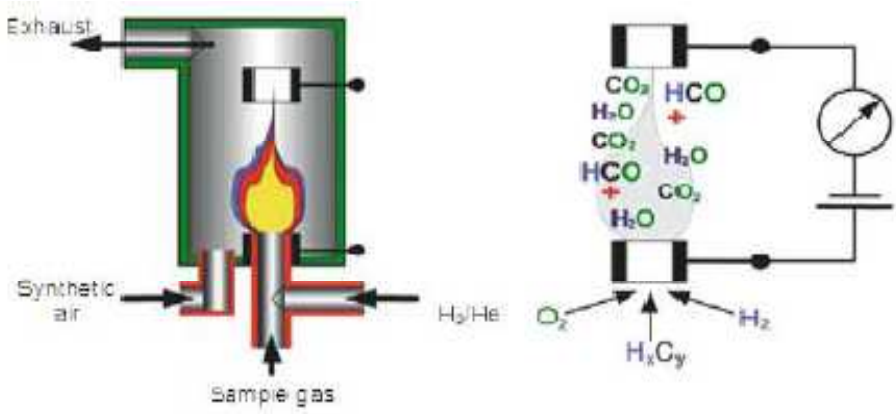

Figure 8: HC Measuring System Principle

\section{Fuel Testing}

Some properties of gasoline A92 are shown in Table 2.

Table 2: Characteristics of Gasoline A92

\begin{tabular}{|c|l|c|}
\hline No. & \multicolumn{1}{|c|}{ Specifications } & Value \\
\hline 1 & Octane number & 92 \\
\hline 2 & Low heat value LHV $(\mathrm{kJ} / \mathrm{kg})$ & 43690 \\
\hline 3 & Lower Flammable Limit $(\% \mathrm{~V})$ & 0,60 \\
\hline 4 & Extinguishing temperature $(\mathrm{oC})$ & 650 \\
\hline 5 & Self-ignition limit concentration $(\%)$ & $5 \div 15$ \\
\hline 6 & Burning speed $(\mathrm{m} / \mathrm{s})$ & 0,43 \\
\hline 7 & Minimum Ignition Energy $(\mathrm{mJ})$ & 0,26 \\
\hline 8 & Membrane temperature $(\mathrm{K})$ & 2266 \\
\hline 9 & H/C ratio & $1 / 5,7$ \\
\hline 10 & Theoretical air/ fuel ratio & 14,7 \\
\hline
\end{tabular}




\section{RESULTS AND DISCUSSIONS}

The regular operation region of the engine as described above has torque divided into 3 times $\mathrm{M}=32$ [Nm], $\mathrm{M}=$ $26[\mathrm{Nm}], \mathrm{M}=22[\mathrm{Nm}]$ and the corresponding speed $\mathrm{n}=1700, \mathrm{n}=2000[\mathrm{rpm}], \mathrm{n}=2300[\mathrm{rpm}], \mathrm{n}=2500[\mathrm{rpm}], \mathrm{n}=2800$ [rpm] for surveying.

\section{Economic and Energy Indicators of the Engine}

After running the test, the fuel consumption characteristic is shown in Figure 9, Figure 10, Figure 11. The results show that:

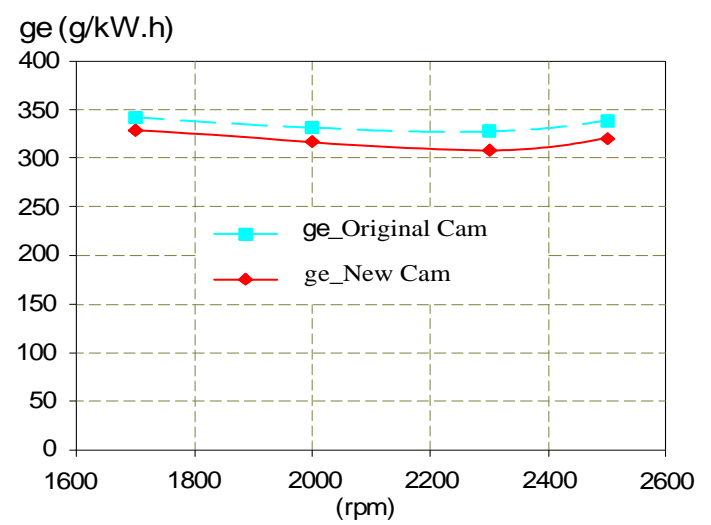

Figure 9: Fuel Consumption with Torque of $32 \mathrm{Nm}$

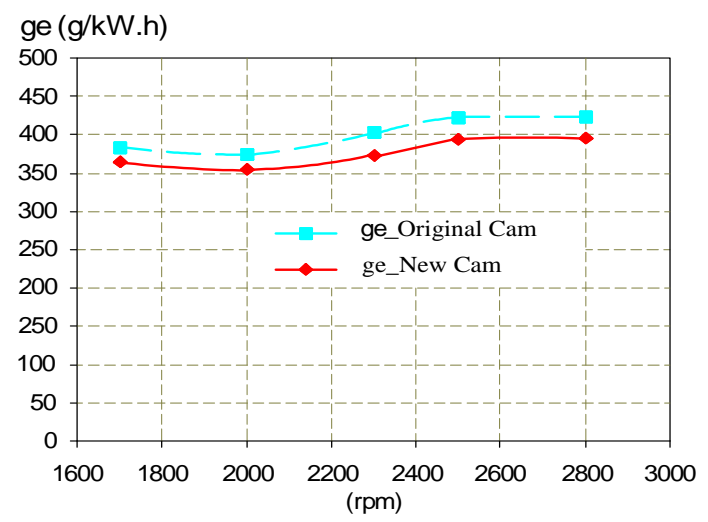

Figure 10: Fuel Consumption with Torque of $26 \mathrm{Nm}$

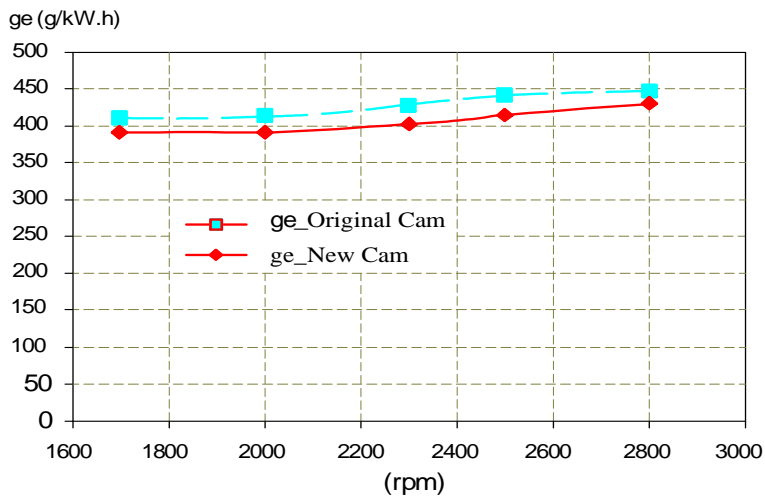

Figure 11: Fuel Consumption with Torque of $22 \mathrm{Nm}$

When changing the angle of the air distribution and the cam profile in the regular work area of the internal 
combustion engine, the fuel economy is significantly improved. Experimental data were obtained when using old camshafts and new camshafts at different load modes, with average fuel consumption reduction of $5.06 \%$.

At this stage of operation with the new early opening and lately closing valve, the fuel consumption is reduced compared to the original engine at all speed modes. Especially in the speed mode $\mathrm{n}=2300$ [rpm], M= 26 [N. m], the fuel consumption will experience a maximum reduction of $7.8 \%$. The fuel consumption in the whole region with $\mathrm{M}=26$ [N. $\mathrm{m}$ ] was reduced an average of $6.3 \%$

\section{Environmental Parameters of the Engine}

From the calculation results, we can construct the emissions graph corresponding to each torque value according to the speed as shown below:
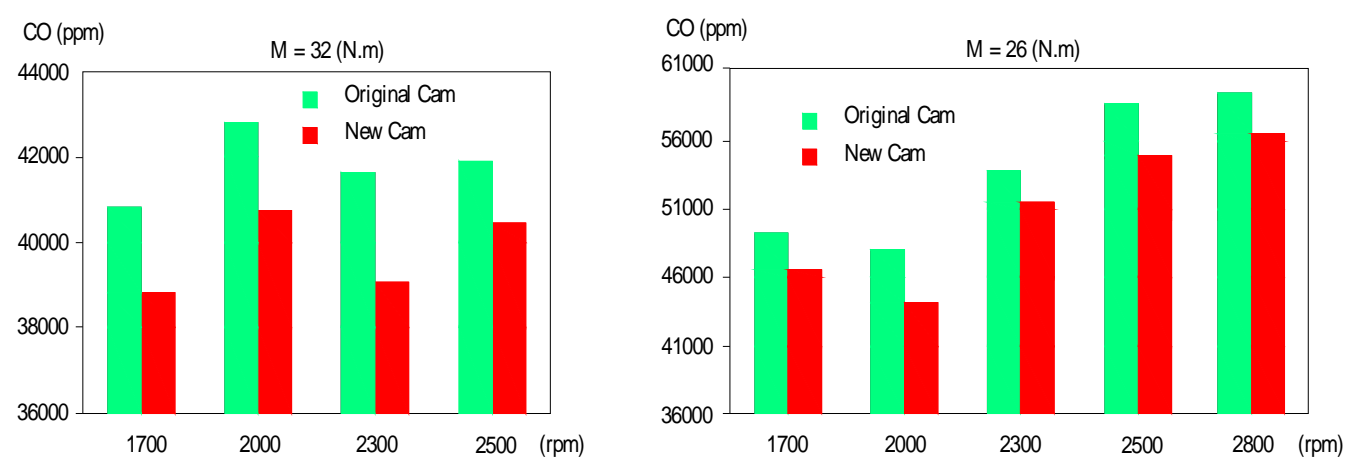

Figure 12: CO Emissions with Original and New Camshafts

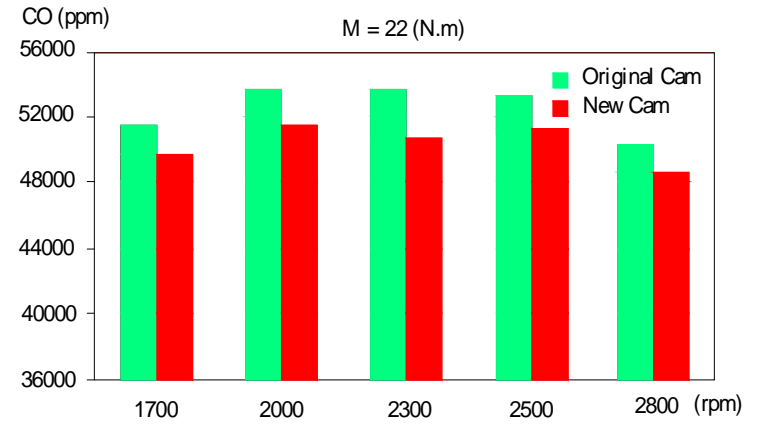

Figure 13: CO Emissions with Original and New Camshafts in $M=22$ N. $m$

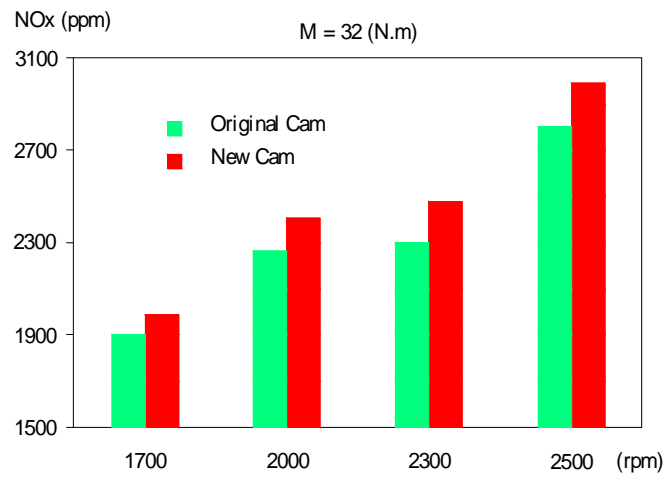

Figure 14: NOx Emissions with Original, New Camshafts in $M=32$ N. m 

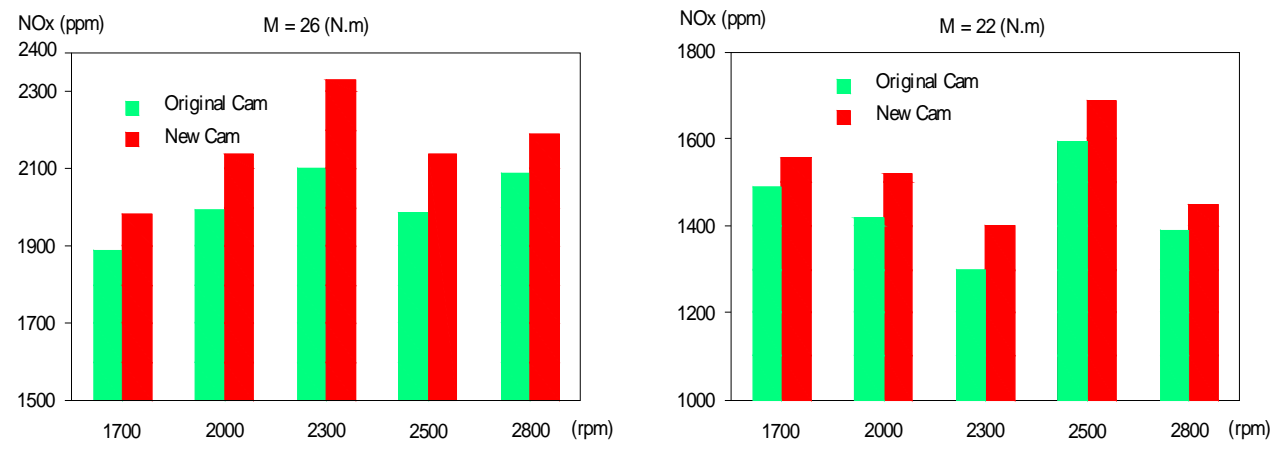

Figure 15: NOx Emissions with Original and New Camshafts

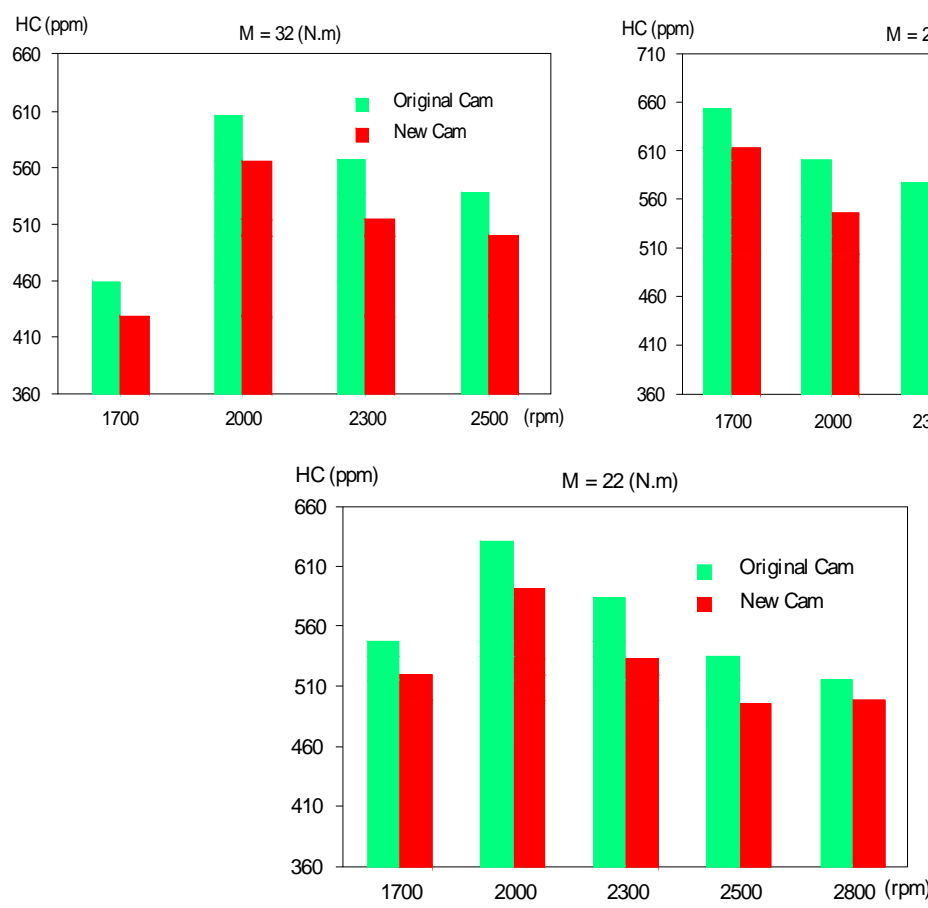

Figure 16: HC Emissions with Original and New Camshafts

The result of the emission analysis from Figure 12, Figure 13, Figure 14, Figure 15, Figure 16 shows that the CO and $\mathrm{HC}$ emissions are lower than the original engine at all speed regimes. Especially in the speed mode $\mathrm{n}=2300[\mathrm{rpm}], \mathrm{M}$ $=26[\mathrm{~N} . \mathrm{m}]$, the largest reduction in $\mathrm{CO}$ is $8 \%$, the largest decrease of $\mathrm{HC}$ is $12.8 \%$. At the moment of $\mathrm{M}=26[\mathrm{~N} . \mathrm{m}], \mathrm{CO}$ decreased by $5.2 \%$ on average, and $\mathrm{HC}$ decreased by an average of $8.2 \%$.

NOx emissions increased slightly by about $10.1 \%$ compared to primitive engines, with an average reduction of $7.2 \%$ in the $\mathrm{M}=26[\mathrm{~N} . \mathrm{m}]$. However, with gasoline engines, NOx emissions are very small.

\section{CONCLUSIONS}

From the results of theoretical and empirical research, some conclusions can be drawn:

- A new camshaft design was developed to match the working mode of the gasoline engine when used on hybrid vehicles and was installed on the engine to conduct experiments to determine the effect of changing the valve timing and cam profile designed.

- Engine with improved camshaft works stability, improve the performance of the engine on the work area 
regularly. According to the largest reduction in fuel consumption data at $7.5 \%$ at speed $n=2300[\mathrm{rpm}]$ and $\mathrm{M}=26$ $[\mathrm{Nm}]$, the average fuel consumption in the whole region decreased by $6.3 \%$; the reduction of $\mathrm{CO}$ and $\mathrm{HC}$ compared to the original engine has confirmed the effectiveness of improving the working cycle of the gasoline engine when used on hybrid vehicles by changing the valve timing

- The results of theoretical calculations are not different much from the results of empirical research, which confirms the correctness of the model, calculation method and software selection.

\section{REFERENCES}

1. Jinxing Zhao, Min Xu, Mian Li, Bin Wang, Shuangzhai Liu, Design and optimization of an Atkinson cycle engine with the Artificial Neural Network Method, National Engineering Laboratory for the Automotive Electronic Control Technology, Shanghai Jiao Tong University, 2012.

2. R. J. Saunders and E. A. Abdul-Wahab (1989), Variable Valve Closure Timing for load Control and the Otto Atkinson Cycle Engine, Department of Mechanical \& Process Engineering University of Sheffield, International Congress and Exposition Detroit, Michigan, February 27.

3. Zhengmao Ye, Frank Washko, Ming-Chia Lai, Frank Washko "Genetic Algorithm Optimization of Fuel Economy for PFI Engine with VVT-VCR” Department of Mechanical Engineering Wayne State University Detroit, MI 48202.

4. Victor Gheorghiu (2003), Enhancement potential of the thermal conversion efficiency of ice cycles especially for use in hybrid vehicles, Hamburg University of Applied Sciences, Germany.

5. Nobuki Kawamoto, Kiyoshi Naiki, Toshihiro Kawai, Takasuke Shikida and Mamoru Tomatsuri(2009), Development of New 1.8-Liter Engine for Hybrid Vehicles, SAE paper 2009.

6. Amy Raskin, Saurin Shah(2006), The Emergence of Hybrid Vehicles, University of Pennsylvania, Columbia University, AllianceBernstein Research on Strategic Change, June 2006.

7. Mark Warren (2011), The Toyota Prius hybrid is packed with technology, put there to achieve its design goal of maximum efficiency, journal Motor USA, February 2011.

8. Bhaskar, K., Sassykova, L. R., Prabhahar, M., \& Sendilvelan, S. (2017). Effect of dimethoxy-methane (C3H8O2) additive on emission characteristics of a diesel engine fueled with biodiesel. International Journal of Mechanical and Production Engineering Research and Development, 8(1), 399-406.

9. K. Muta, M. Yamazaki, and J. Tokieda(2004), Development of new-generation hybrid system THS II-Drastic improvement of power performance and fuel Economy, SAE Technical Paper 2004-01-0064, 2004.

10. VanTuan Nguyen (2018), Design and Manufacturing Camshaft Using on Hybrid Vehicles, International Journal of Mechanical Engineering and Technology (IJMET) Volume 9, Issue 6, June 2018, pp. 277-284.

11. M. H. Westbrook(2001), The Electric and Hybrid Electric Car, Society of Automotive Engineers, Warrendale, PA, 2001, p. 198. Multifaceted Complexity of Batteries 155. 